\title{
Structural characteristics, quality and plant biodiversity in forest types at Xuan Son national park, Phu Tho province
}

\author{
Trieu V. Nguyen ${ }^{1 *}$, \& Hung, M. Bui ${ }^{2}$ \\ ${ }^{1}$ Faculty of Forestry, Vietnam National University of Forestry, Ha Noi, Vietnam \\ ${ }^{2}$ International Cooperation Department, Vietnam National University of Forestry, Ha Noi, Vietnam
}

ARTICLE INFO
Research paper
Received: January 08, 2017
Revised: March 24, 2018
Accepted: April 04, 2018
Keywords
Forest structure
Forest tree growth
Tree biodiversity
Xuan Son national park
*Corresponding author
Nguyen Van Trieu
Email: trieulamsinh@gmail.com

\begin{abstract}
Forest structure plays a very important role in the sustainable management of forest resources. Research established 20 plots. The plot area is $900 \mathrm{~m}^{2}(30 \mathrm{~m} \times 30 \mathrm{~m})$ for 4 forest types: IIA, IIB, IIIA1 and IIIA3. Results showed that average diameter of four stages is IIA: $11.25 \mathrm{~cm}$; IIB: $12.81 \mathrm{~cm}$; II: $1: 15.94 \mathrm{~cm}$ and IIIA3: $20.30 \mathrm{~cm}$. The mixed linear model demonstrated that growth in both diameter and height between forest states was significantly different $(P<$ 0.05). Weibull and J-shape functions can simulate well for $75 \%$ of experimental distributions. Path analysis showed that for all four states, direct influence (AHTT) had a greater absolute value than the indirect effect (AHGT). Principal component analysis diagrams showed that for all four types, the quality of forest trees was closely related to canopy width, total height and diameter at breast height. The difference in the quality of the trees between the four states was really significant, as the Sig value of the Chi-square test is 0.000 (less than 0.05). Stages IIA and IIB had mainly species of pioneer species, while IIIA1 and IIIA3 had more shade tolerant species. Stage IIIA3 had the highest level of species diversity.
\end{abstract}

Cited as: Nguyen, T. V., \& Bui, H. M. (2018). Structural characteristics, quality and plant biodiversity in forest types at Xuan Son national park, Phu Tho province. The Journal of Agriculture and Development 17(4), 53-61. 


\title{
Cấu trúc, chất lượng và đa dạng thực vật thân gỗ giữa các thảm thực vật, vườn quốc gia Xuân Sơn, tỉnh Phú Thọ
}

\author{
Nguyễn Văn Triệu ${ }^{1 *}$ \& Bùi Mạnh Hưng ${ }^{2}$ \\ ${ }^{1}$ Khoa Lâm Học, Trường Đại Học Lâm Nghiệp, Hà Nội \\ ${ }^{2}$ Phòng Hợp Tác Quốc Tế, Trường Đại Học Lâm Nghiệp, Hà Nội
}

\author{
THÔNG TIN BÀI BÁO \\ Bài báo khoa học \\ Ngày nhận: 08/01/2017 \\ Ngày chỉnh sửa: 24/03/2018 \\ Ngày chấp nhận: 04/04/2018

\section{Từ khóa \\ Cấu trúc rừng \\ Đa dạng thực vật thân gỗ \\ Sinh trưởng \\ Vườn Quốc gia Xuân Sơn} \\ *Tác giả liên hệ \\ Nguyễn Văn Triệu \\ Email: trieulamsinh@gmail.com
}

\section{TÓM TẮT}

Cấu trúc rừng đóng một vai trò rất quan trọng trong quản lý tài nguyên rừng bền vững. Nghiên cứu đã tiến hành bố trí 20 ô tiêu chuẩn (OTC) điển hình tạm thời với diện tích $900 \mathrm{~m}^{2}(30 \mathrm{~m} \times 30 \mathrm{~m})$ của bốn trạng thái: IIA, IIB, IIIA1 và IIIA3. Kết quả cho thấy rằng đường kính ở 4 trạng thái lần lượt là IIA: $11,25 \mathrm{~cm}$; IIB: $12,81 \mathrm{~cm}$; IIIA1: $15,94 \mathrm{~cm}$ và IIIA3: 20,30 cm. Mô hình tuyến tính hỗn hợp chứng minh rằng sinh trưởng cả về đường kính và chiều cao giữa các trạng thái rừng là thực sự khác biệt $(P<0,05)$. Hai hàm Weibull và khoảng cách có thể mô phỏng tốt cho $75 \%$ phân bố thực nghiệm. Hệ số đường ảnh hưởng cho thấy rằng với cả bốn trạng thái thì hệ số ảnh hưởng trực tiếp (AHTT) điều có giá trị tuyệt đối lớn hơn hệ số ảnh hưởng gián tiếp (AHGT). Biểu đồ của phân tích thành phần chính cho thấy rằng với cả bốn loại trạng thái rừng thì chất lượng cây rừng có mối quan hệ khá chặt với đường kính tán, chiều cao dưới cành và đường kính ngang ngực. Sự khác biệt vệ chất lượng cây rừng giữa 4 trạng thái là thực sự rõ rệt, do giá trị $P$ của trắc nghiệm Chi-square là 0,000 (nhỏ hơn 0,05 ). Ở trạng thái IIA và IIB chủ yếu các loài cây tiên phong ưu sáng mọc nhanh, còn ở trạng thái IIIA1 và IIIA3 xuất hiện thêm nhiều loài cây chịu bóng. Trạng thái trạng thái IIIA3 có mức độ da dạng sinh học loài là cao nhất.

\section{1. Đắt Vấn Đề}

Trong những năm hiện nay trên thế giới chung và Việt Nam ta nói riêng đã và đang gặp phải nhiều thiên tai, hạn hán, mưa bão, lũ lụt... nguyên nhân chính là biến đổi khí hậu toàn cầu. Một trong những giải pháp hàng đầu được cả thế giới quan tâm đó là bảo tồn và khôi phục hệ sinh thái rừng nhằm cân bằng hệ sinh thái và giảm hiện tượng hiệu ứng nhà kính. Nghiên cứu cấu trúc và đa dạng sinh học loài của các thảm thực vật là rất quan trọng để đề xuất các giải pháp quản lý tài nguyên rừng bền vững. Bởi lẽ, chúng là những yếu tố cốt lõi giúp các nhà lâm nghiệp hiểu được đối tượng mình đang quản lý. Cấu trúc sẽ phản ánh được các chức năng sinh thái của các loại thảm thực vật. Đa dạng sinh học loài sẽ bị tác động trực tiếp bởi cấu trúc tần số đường kính (Spies, 1998). Phân loại được cấu trúc rừng là cơ sở rất quan trọng để đánh giá và kiểm soát các hệ sinh thái rừng (Gao \& ctv., 2014; Valbuena, 2015).

Các vườn quốc gia, các khu bảo tồn giữ một vai trò cực kỳ quan trọng trong việc kiểm soát lượng phát thải $\mathrm{CO}_{2}$ và giảm thiểu hiệu ứng nhà kính tại Việt Nam. Vườn quốc gia Xuân Sơn cũng không là ngoại lệ. Vườn có diện tích vùng đệm 18.369 ha, trong đó diện tích vùng lõi là 15.048 (ha) khu vực bảo vệ nghiêm ngặt là 11.148 (ha) (Tran, 2010). Xuân Sơn được đánh giá là rừng có đa dạng sinh thái phong phú, đa dạng sinh học cao, đa dạng địa hình kiến tạo nên đa dạng cảnh quan, có nhiều loài động thực vật có giá trị cao về nghiên cứu khoa học và bảo vệ nguồn gen (Tran, 2010). Tuy nhiên, hiện nay việc nghiên cứu về cấu trúc rừng và đa dạng thực vật tầng cây cao ở vườn quốc gia Xuân Sơn còn hạn chế và thiếu rất nhiều thông tin. Nên những điều này đã ảnh hưởng rõ rệt tới việc quản lý tài nguyên rừng tại đây. 
Để giải quyết vấn đề này, bài báo sẽ tập trung vào: 1) Phân tích đặc điểm cấu trúc tầng cây cao tại các trạng thái rừng khác nhau; 2) Phân tích khác biệt về chất lượng cây rừng giữa các thảm thực vật và 3 ) Đánh giá tổ thành loài và đa dạng thực vật thân gỗ tại khu vực nghiên cứu. Chúng sẽ là cơ sở vững chắc để quản lý và phát triển tài nguyên rừng tại khu vực nghiên cứu một cách bền vững trong tương lai.

\section{Vật Liệu và Phương Pháp Nghiên Cứu}

\subsection{Phương pháp thu thập số liệu}

Nghiên cứu đã tiến hành bố trí 20 ô tiêu chuẩn (OTC) điển hình tạm thời với diện tích $900 \mathrm{~m}^{2}$ $(30 \mathrm{~m} \times 30 \mathrm{~m})$ của bốn trạng thái: IIA, IIB, IIIA1 và IIIA3. Mỗi trạng thái lập 5 OTC. Phương pháp rút mẫu được áp dụng là phương pháp phân tầng ngẫu nhiên để lựa chọn vị trí các OTC. Đây là phương pháp phù hợp khi điều tra tài nguyên rừng, bởi lẽ các hệ sinh thái rừng thường không đồng nhất (Shiver \& Borders, 1996). Các OTC được lập năm 2016 tại vườn với sự hỗ trợ kinh phí từ đề tài cơ sở Trường Đại học Lâm Nghiệp. Sơ đồ vị trí các OTC được trình bày trong Hình 1.

Trong các OTC, tiến hành điều tra, xác định tên loài, đo đường kính ngang ngực, chiều cao vút ngọn, đường kính tán, phân loại chất lượng cây rừng thành tốt, trung bình và xấu của tất cả những cây có đường kính lớn hơn $6 \mathrm{~cm}(\mathrm{Vu} \&$ Pham, 1996).

\subsection{Phương pháp xử lý số liệu}

Toàn bộ số liệu được xử lý bằng SPSS 24. Cụ thể nội dung và phương pháp như sau:

\subsubsection{Phân tích cấu trúc và sinh trưởng rừng}

- Kiểm tra sự thuần nhất số liệu, sinh trưởng và so sánh sinh trưởng cây rừng:

Để kiểm tra sự thuần nhất về số liệu giữa các ô, biểu đồ đám mây điểm hai chiều theo kích thước cây được xây dựng để kiểm tra. Quá trình tính toán được thực hiện trên SPSS (Ho, 2013; Bui \& Le, 2017).

Đặc điểm sinh trưởng của cây rừng được phân tích thong qua các đặc trưng mẫu như dung lượng mẫu, số trung bình, phương sai, sai tiêu chuẩn, giá trị nhỏ nhất, giá trị lớn nhất, khoảng biến động, độ lệch, độ nhọn và sai số của trung bình

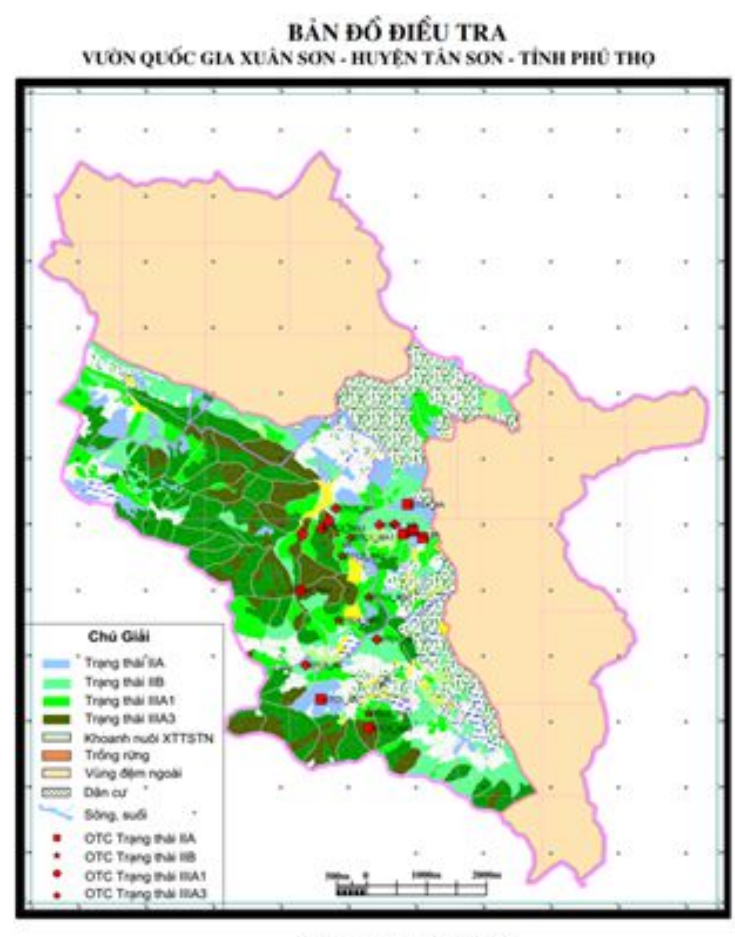

Tỷ lệ $1: 25000$

Hình 1. Vị trí của các ô tại vườn quốc gia Xuân Sơn.

mẫu (Zar, 2010). Những đại lượng này được tính toán cho 2 đại lượng điều tra là đường kính ngang ngực và chiều cao vút ngọn.

So sánh sinh trưởng của cây rừng giữa các trạng thái rừng được thực hiện nhờ phân tích mô hình tuyến tính hỗn hợp. Đây là phương pháp mới được áp dụng, nó có khả năng kiểm tra được tính độc lập của số liệu giữa các OTC và đánh gia được các ảnh hưởng ngẫu nhiên lên các tập số liệu (Bui \& Bui, 2017; Bui \& Le, 2017).

- So sánh cấu trúc tần số:

Để phân tích biến đổi cấu trúc tần số cho đại lượng điều tra đường kính và chiều cao cây rừng thì sau khi phân bố tần số thực nghiệm được tạo ra, chúng sẽ được sử dụng để mô hình hóa theo 2 phân bố lý thuyết hay sử dụng. Đó là phân bố Weibull, phân bố hàm Khoảng cách để tìm được các quy luật tồn tại trong quần xã (Nguyen \& ctv., 2006).

\subsubsection{Phân tích chất lượng cây rừng}

Hệ số đường ảnh hưởng đã kiểm tra mức độ ảnh hưởng của các nhân tố đường kính ngang ngực, chiều cao vút ngọn và đường kính tán tới chất 
lượng cây rừng. Đồng thời tính toán hệ số ảnh hưởng trực tiếp và hệ số ảnh hưởng gián tiếp của các đại lượng điều tra đến chất lượng cây rừng (Bui \& Le, 2017).

Phân tích thành phần chính $(\mathrm{PCA})$ được sử dụng để phân loại mối quan hệ giữa các đại lượng điều tra như đường kính, chiều cao và chất lượng cây rừng. Phương pháp này cũng được sử dụng để phân nhóm các yếu tố này thành nhóm quan hệ chặt, ít đối kháng và đối kháng cao. Cuối cùng, chất lượng cây rừng giữa các trạng thái được so sánh bởi tiêu chuẩn Chi-square (Bui \& Le, 2017).

\subsubsection{Tổ thành và đa dạng sinh học loài}

- Xác định cấu trúc tổ thành thực vật rừng:

Công thức tổ thành biểu thị theo số cây được xác định như sau:

$$
\begin{gathered}
\mathrm{K}_{1} \mathrm{a}_{1}+\mathrm{K}_{2} \mathrm{a}_{2}+\mathrm{K}_{3} \mathrm{a}_{3}+\ldots+\mathrm{K}_{\mathrm{n}} \mathrm{a}_{\mathrm{n}} \\
\text { với: } \mathrm{K}_{\mathrm{i}}=\mathrm{n}_{\mathrm{i}} / \mathrm{N} \times 10
\end{gathered}
$$

- Xác định tính đa dạng trong các trạng thái rừng:

Để đánh giá mức độ da dạng sinh học các loài tại khu vực nghiên cứu, các chỉ số đa dạng sinh học sau đã được sử dụng và tính toán (Spies \& Franklin, 1996; Kindt \& Coe, 2005; Bui, 2016).

Chỉ số độ phong phú loài Margalef (1958):

$$
\mathrm{d}=(\mathrm{S}-1) / \log \mathrm{N}
$$

Chỉ số đa dạng sinh học loài $\mathrm{H}^{\prime}$ (Shannon Wiener's index) (1963):

$$
\mathrm{H}^{\prime}=-\sum_{\mathrm{i}=1}^{\mathrm{m}} \mathrm{p}_{\mathrm{i}} \ln \left(\mathrm{p}_{\mathrm{i}}\right)
$$

Chỉ số đồng đều Pielou $\left(\mathrm{J}^{\prime}\right): \mathrm{J}^{\prime}=\mathrm{H}^{\prime} / \ln (\mathrm{S})$

Chỉ số độ bình quân Sheldom:

$$
\mathrm{E}_{\mathrm{S}}=\frac{-\mathrm{e}^{\sum \mathrm{p}_{\mathrm{i}} \log \mathrm{p}_{\mathrm{i}}}}{\mathrm{S}}
$$

\section{Kết Quả và Thảo Luận}

\subsection{Khác biệt cấu trúc và sinh trưởng}

- Sự thuần nhất của số liệu ở mỗi trạng thái:

Để giảm thiểu số lượng phân tích, phản ánh khách quan hơn các trạng thái, số liệu giữa các ô của cùng trạng thái được gộp lại. Bởi vì chúng khá thuần nhất, điều này thể hiện trong biểu đồ đám mây điểm giữa đường kính, chiều cao của các ô như trong hình dưới đây. Sự thuần nhất biểu thị cả về mặt kích thước cây. Biểu đồ của các trạng thái cho thấy rằng các điểm tương ứng của các ô với kích thước khác nhau hòa lẫn, tương đối sát nhau và không có sự biệt dị rõ rệt nào cả về mặt kích thước cây.
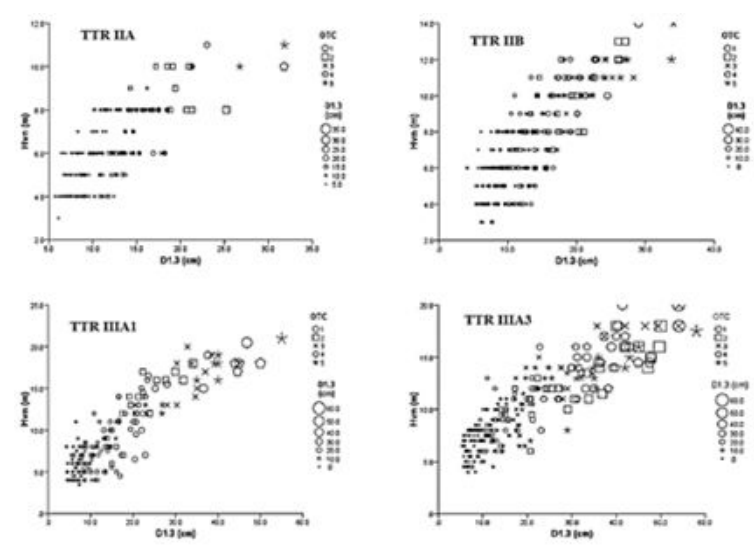

Hình 2. Biểu đồ đám mây điểm giữa đường kính và chiều cao.

- Đặc trưng sinh trưởng của các đại lượng:

Kết quả tính toán đặc trưng mẫu cho các đại lượng sinh trưởng đường kính ngang và chiều cao vút ngọn của các trạng thái được thể hiện vào Bảng 1.

Từ kết quả bảng trên cho ta thấy đường kính ngang ngực và chiều cao vút ngọn tăng dần theo trạng thái. Đường kính ở 4 trạng thái lần lượt là IIA: $11,25 \mathrm{~cm}$; IIB: $12,81 \mathrm{~cm}$; IIIA1: $15,94 \mathrm{~cm}$ và IIIA3: 20,30 cm. Đồng thời phạm vi biến động của đường kính và chiều cao cũng tăng theo trạng thái. Điều này thể hiện qua sai tiêu chuẩn IIA là $4,31 \mathrm{~cm}$; IIB là $5,84 \mathrm{~cm}$; IIIA1 là $11,00 \mathrm{~cm}$ và IIIA3 là 13,01 cm. Đây là kết quả sinh trưởng, phát triển và cạnh tranh của cây rừng, là nguyên nhân dẫn đến việc ở trạng thái rừng càng già thì phân hóa cây rừng càng lớn.

- So sánh sinh trưởng đường kính và chiều cao giữa các trạng thái:

Kết quả phân tích bằng mô hình tuyến tính hỗn hợp để kiểm tra sự khác biệt về sinh trưởng của cây rừng giữa các trạng thái được thể hiện trong Bảng 2.

Kết quả bảng trên cho thấy rằng sinh trưởng cả về đường kính và chiều cao giữa các trạng thái rừng là thực sự khác biệt, bởi lẽ toàn bộ các giá trị Sig đều nhỏ hơn 0,05 . Về cả đường kính và 
Bảng 1. Kết quả tính toán đặc trưng mẫu về đường kính và chiều cao ở 4 trạng thái

\begin{tabular}{ccccccccc}
\hline \multirow{2}{*}{ Đặc trưng thống kê } & \multicolumn{4}{c}{$\mathrm{D}_{1,3}(\mathrm{~cm})$} & \multicolumn{5}{c}{ Hvn $(\mathrm{m})$} \\
\cline { 2 - 8 } & IIA & IIB & IIIA1 & IIIA3 & IIA & IIB & IIIA1 & IIIA3 \\
\hline Trung bình & 11,25 & 12,81 & 15,94 & 20,30 & 6,03 & 7,13 & 9,34 & 10,22 \\
Sai tiêu chuẩn & 4,31 & 5,84 & 11,00 & 13,01 & 1,59 & 2,49 & 4,54 & 3,76 \\
Phương sai & 18,61 & 34,16 & 120,92 & 169,27 & 2,52 & 6,19 & 20,59 & 14,13 \\
Độ lệch & 3,85 & 0,64 & 1,16 & $-0,18$ & 0,27 & $-0,54$ & $-0,56$ & $-0,59$ \\
Độ nhộn & 1,59 & 1,03 & 1,33 & 0,90 & 0,78 & 0,57 & 0,76 & 0,54 \\
Phạm vi biến động & 26,11 & 29,94 & 50,70 & 52,59 & 8,00 & 11,00 & 17,50 & 16,00 \\
Giá trị lớn nhất & 5,7 & 4,1 & 4,3 & 5,4 & 3,0 & 3,0 & 3,5 & 4,0 \\
Giá trị nhỏ nhất & 31,8 & 34,1 & 55,0 & 58,0 & 11,0 & 14,0 & 21,0 & 20,0 \\
Dung lượng mẫu & 256,0 & 286,0 & 186,0 & 242,0 & 256,0 & 286,0 & 186,0 & 242,0 \\
\hline
\end{tabular}

Bảng 2. Kết quả so sánh bằng mô hình tuyến tính hỗn hợp

\begin{tabular}{|c|c|c|c|c|c|c|c|c|}
\hline \multirow{2}{*}{ Đại lượng } & \multirow{2}{*}{ Tham số } & \multirow{2}{*}{$\begin{array}{l}\text { Ước } \\
\text { lượng }\end{array}$} & \multirow{2}{*}{$\begin{array}{l}\text { Sai } \\
\text { số }\end{array}$} & \multirow{2}{*}{$\begin{array}{l}\text { Bậc } \\
\text { tự do }\end{array}$} & \multirow{2}{*}{$\mathrm{t}$} & \multirow{2}{*}{ Sig. } & \multicolumn{2}{|c|}{ Ước lượng } \\
\hline & & & & & & & Cận dưới & Cận trên \\
\hline \multirow{5}{*}{$\begin{array}{c}\text { Biến } \\
\text { đường kính }\end{array}$} & Hệ số & 20,30 & 0,58 & 966,00 & 35,22 & 0,00 & 19,17 & 21,43 \\
\hline & Trạng thái IIA & $-9,05$ & 0,80 & 966,00 & $-11,26$ & 0,00 & $-10,62$ & $-7,47$ \\
\hline & Trạng thái IIB & $-7,48$ & 0,78 & 966,00 & $-9,55$ & 0,00 & $-9,02$ & $-5,94$ \\
\hline & Trạng thái IIIA1 & $-4,35$ & 0,87 & 966,00 & $-4,97$ & 0,00 & $-6,06$ & $-2,63$ \\
\hline & Trạng thái IIIA3 & $0 \mathrm{~b}$ & 0,00 & & & & & \\
\hline \multirow{5}{*}{ Chiều cao } & Hệ số & 10,23 & 0,20 & 966,00 & 49,94 & 0,00 & 9,83 & 10,63 \\
\hline & Trạng thái IIA & $-4,25$ & 0,29 & 966,00 & $-14,89$ & 0,00 & $-4,82$ & $-3,69$ \\
\hline & Trạng thái IIB & $-3,09$ & 0,28 & 966,00 & $-11,12$ & 0,00 & $-3,64$ & $-2,55$ \\
\hline & Trạng thái IIIA1 & $-0,91$ & 0,31 & 966,00 & $-2,92$ & 0,00 & $-1,52$ & $-0,30$ \\
\hline & Trạng thái IIIA3 & ob & 0,00 & & & & & \\
\hline
\end{tabular}

chiều cao, trạng thái IIIA3 đều là lớn nhất, sau đó giảm dần tới IIIA1, IIB và IIA.

\subsection{Phân bố số cây theo cỡ đường kính, chiều cao}

- Phân bố tần số cho đường kính và chiều cao: Phân bố số cây theo đường kính thường có dạng giảm liên tục từ tổ đầu tiên. Còn phân bố số cây theo chiều cao thì đỉnh có dạng lệch trái, tức là đỉnh của đường cong thường ở tổ thứ 2 hoặc thứ 3 . Điều này được thể hiện rõ rang hỡn trong biểu đồ không gian phân bố số cây theo đường kính và chiều cao như sau. Đây cũng là quy luật tương đối phổ biến được tìm thấy trong các nghiên cứu khác cho rừng nhiệt đới (Richards, 1996; Bui, 2016).

- Mô phỏng phân bố thực nghiện theo phân bố lý thuyết:

Từ kết quả phân bố thực nghiệm số cây theo đường kính và chiều cao thu nhận được, hai phân bố lý thuyết là phân bố Khoảng cách và Weibull đã được sử dụng để mô hình hóa để tìm ra quy

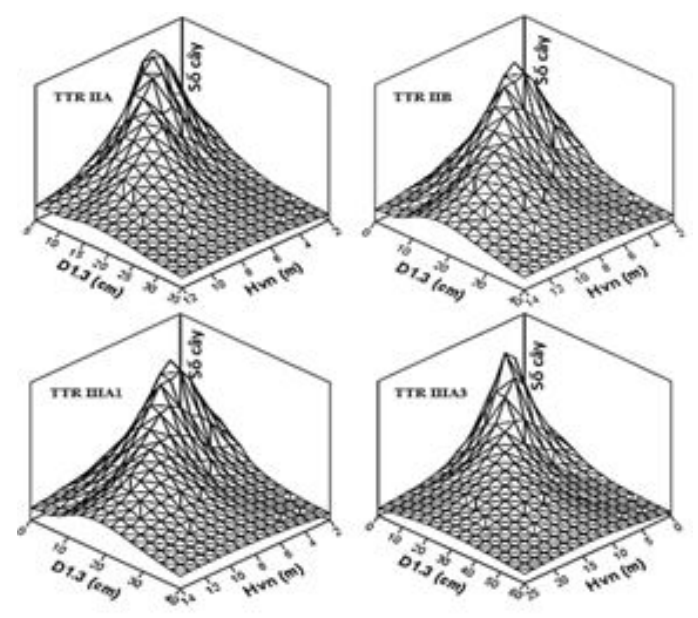

Hình 3. Phân bố tần số cho đường kính và chiều cao ở 4 trạng thái.

luật khách quan tồn tại trong các thảm thực vật. Kết qủa được trình bày trong Bảng 3 .

Kết quả bảng trên cho thấy rằng cả hai hàm lý thuyết được chọn có khả năng mô phỏng rất 
Bảng 3. Mô phỏng phân bố thực nghiện theo hàn phâm bố Khoảng cách và Hàm Weibull

\begin{tabular}{|c|c|c|c|c|c|c|c|c|}
\hline \multirow[t]{2}{*}{ Hàm Phân Bố } & \multirow{2}{*}{$\begin{array}{c}\text { Phân } \\
\text { Bố }\end{array}$} & \multirow{2}{*}{$\begin{array}{l}\text { Trạng } \\
\text { thái }\end{array}$} & \multicolumn{3}{|c|}{$\begin{array}{c}\text { Các } \\
\text { tham số }\end{array}$} & \multirow[t]{2}{*}{$\chi^{\text {tinh }}$} & \multirow[t]{2}{*}{$\chi^{\text {bảng }}$} & \multirow[t]{2}{*}{ Kết luận } \\
\hline & & & $\alpha$ & $\gamma$ & $\lambda$ & & & \\
\hline \multirow{8}{*}{ Hàm Khoảng Cách } & \multirow{4}{*}{$\mathrm{N} / \mathrm{D}$} & IIA & 0,46 & 0,01 & & 9,61 & 7,82 & $\mathrm{H}_{0}^{+}$ \\
\hline & & IIB & 0,57 & 0,04 & & 4,33 & 9,49 & $\mathrm{H}_{0}^{-}$ \\
\hline & & IIIA2 & 0,70 & 0,09 & & 7,17 & 11,07 & $\mathrm{H}_{0}^{-}$ \\
\hline & & IIIA3 & 0,76 & 0,03 & & 11,84 & 14,07 & $\mathrm{H}_{0}^{-}$ \\
\hline & \multirow{4}{*}{$\mathrm{N} / \mathrm{H}$} & IIA & 0,35 & 0,10 & & 8,36 & 5,99 & $\mathrm{H}_{0}^{+}$ \\
\hline & & IIB & 0,53 & 0,12 & & 28,96 & 7,82 & $\mathrm{H}_{0}^{+}$ \\
\hline & & IIIA2 & 0,69 & 0,07 & & 11,45 & 11,07 & $\mathrm{H}_{0}^{+}$ \\
\hline & & IIIA3 & 0,68 & 0,05 & & 25,97 & 11,07 & $\mathrm{H}_{0}^{+}$ \\
\hline \multirow{8}{*}{ Hàm Weibull } & \multirow{4}{*}{$\mathrm{N} / \mathrm{D}$} & IIA & 1,60 & & 0,03 & 81,24 & 9,49 & $\mathrm{H}_{0}^{+}$ \\
\hline & & IIB & 1,80 & & 0,01 & 37,93 & 11,07 & $\mathrm{H}_{0}^{+}$ \\
\hline & & IIIA2 & 1,10 & & 0,05 & 17,94 & 11,07 & $\mathrm{H}_{0}^{+}$ \\
\hline & & IIIA3 & 1,10 & & 0,04 & 18,98 & 15,51 & $\mathrm{H}_{0}^{+}$ \\
\hline & \multirow{4}{*}{$\mathrm{N} / \mathrm{H}$} & IIA & 2,70 & & 0,02 & 10,56 & 5,99 & $\mathrm{H}_{0}^{+}$ \\
\hline & & IIB & 2,20 & & 0,02 & 16,96 & 9,49 & $\mathrm{H}_{0}^{+}$ \\
\hline & & IIIA2 & 1,10 & & 0,12 & 16,55 & 11,07 & $\mathrm{H}_{0}^{+}$ \\
\hline & & IIIA3 & 1,90 & & 0,02 & 9,36 & 12,59 & $\mathrm{H}_{0}^{-}$ \\
\hline
\end{tabular}

tốt cho phân bố thực nghiệm. 75\% kết luận chấp nhận giả thuyết. Trong hai hàm thử nghiệm thì phân bố Weibull có khả năng mô hình hóa tốt hơn, bởi nó mềm dẻo hơn, đặc biệt hàm này có thể suy biến thành hàm giảm khi tham số $\alpha$ bằng 1. Một lần nữa kết quả cho thấy rằng các phân bố đều có dạng giảm hoặc một đỉnh do khai thác chọn nhiều năm.

\subsection{Khác biệt về chất lượng cây rừng}

- Ảnh hưởng của các đại lượng sinh trưởng tới chất lượng cây rừng:

Hệ số đường ảnh hưởng đã kiểm tra mức độ ảnh hưởng của các nhân tố đường kính ngang ngực, chiều cao vút ngọn và đường kính tán tới chất lượng cây rừng. Kết quả được thể hiện trong Bảng 4.

Kết quả trong bảng trên cho thấy rằng trong các nhân tố ảnh hưởng thì $\mathrm{D}_{1,3}$ có quan hệ nghịch biến với chất lượng, còn chiều cao và đường kính tán (Dt) có quan hệ đồng biến với chất lượng. Với cả bốn trạng thái thì hệ số ảnh hưởng trực tiếp $(\mathrm{AHTT})$ điều có giá trị tuyệt đối lớn hơn hệ số ảnh hưởng gián tiếp (AHGT). Điều này chứng tỏ rằng chất lượng của các khu rừng ít bị ảnh hưởng của những nhân tố khác như khí hậu và các đại lượng điều tra khác, mà trực tiếp ảnh hưởng bởi đường kính, chiều cao và đường kính tán cây rừng.
Biểu đồ của phân tích thành phần chính dưới đây cho thấy rằng với cả bốn loại trạng thái rừng thì chất lượng cây rừng có mối quan hệ khá chặt với đường kính tán, chiều cao dưới cành và đường kính ngang ngực. Trong đó quan hệ chặt chẽ nhất với đường kính tán. Vì vậy, để đảm bảo và nâng cao chất lượng cây tốt trong khu vực nghiên cứu thì cần chú ý tới các biện pháp kỹ thuật lâm sinh có lợi cho sự phát triển của tán cây rừng như: tỉa thưa, đảm bảo không gian dinh dưỡng tối ưu. . .
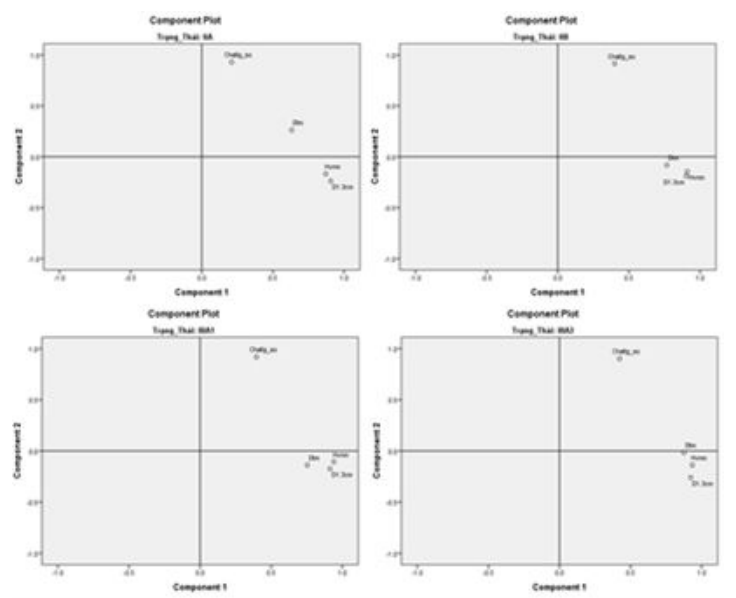

Hình 4. Biểu đồ phân tích thành phần chính.

- Chất lượng cây rừng giữa các trạng thái:

Kết quả thống kê số lượng cây rừng của từng 
Bảng 4. Kết quả hệ số đường ảnh hưởng

\begin{tabular}{ccccccc}
\hline Trạng thái & $\mathrm{D}_{1,3}(\mathrm{~cm})$ & $\mathrm{Hvn}(\mathrm{m})$ & $\mathrm{Dt}(\mathrm{m})$ & $\mathrm{Bx}$ & AHTT & AHGT \\
\hline IIA & $-0,261$ & 0,258 & 0,195 & 0,056 & 0,173 & $-0,117$ \\
IIB & $-0,022$ & 0,193 & 0,113 & 0,065 & 0,051 & 0,014 \\
IIIA1 & $-0,204$ & 0,427 & 0,041 & 0,081 & 0,225 & $-0,144$ \\
IIIA3 & $-0,501$ & 0,498 & 0,326 & 0,155 & 0,605 & $-0,450$ \\
\hline
\end{tabular}

trạng thái theo chất lượng cây rừng được thể hiện dưới Bảng 5.

Kết quả thống kê cho thấy rằng tỷ lệ cây chất lượng tốt cao nhất ở trạng thái IIB $(83,22 \%)$ và thấp nhất ở trạng thái IIIA1 (54,30\%). Tỷ lệ số cây chất lượng bình cao nhất ở trạng thái IIIA1 $(24,73 \%)$ và thấp nhất ở trạng thái IIB $(11,19 \%)$. Giá trị tiêu chuẩn Chi-square tính toán được là 67,76. Sự khác biệt vệ chất lượng cây rừng giữa 4 trạng thái là thực sự rõ rệt, do giá trị Sig của tiêu chuẩn này là 0,000 (nhỏ hơn 0,05 ).

\subsection{Tổ thành và đa dạng loài}

- Tổ thành loài cây tầng cây cao:

Tổ thành là chỉ tiêu biểu thị tỷ trọng của một loài, hay nhóm loài cây chiếm trong lâm phần; dùng để đánh giá tính bền vững, tính ổn định, tính đa dạng sinh học trong hệ sinh thái rừng. Kết quả tính toán trên 20 OTC của vườn quốc gia Xuân Sơn được thống kê và trình bày trong Bảng 6.

Kết quả ở Bảng 6 đã cho thấy được số lượng loài cây chiếm ưu thế có trong lâm phần. Ở trạng thái IIA và IIB là trạng thái phục hồi sau nương rẫy với tổ thành loài cây đa dạng và phong phú với chủ yếu các loài cây tiên phong ưu sáng mọc nhanh như: Núi Nái, Phân Mã, Ba Gạc, Mò Lá Nhỏ...; còn ở trạng thái IIIA1 và IIIA3, sau các quá trình diễn thế thì, xuất hiện thêm nhiều loài cây chịu bóng, các cây không có khả năng cạnh tranh sẽ bị đào thải, cấu trúc rừng ổn định đi vào khép tán với các loài cây gỗ như: Vàng Anh, Chìa vôi, Cà Lồ, Lộc Vừng, Sồi...

- Đa dạng loài tại các trạng thái:

Đa dạng loài là sự phong phú đa dạng về loài trong một quần thể hay trong một tập hợp cá thể sống. Kết quả tính toán các chỉ số đa dạng được thống kê vào Bảng 7 .

Mức độ phong phú của loài được đánh giá qua chỉ số d của Margalef, qua kết quả ở bảng trên cho thấy: Mức độ phong phú về loài nhất là ở trạng thái IIIA1 $(22,47)$ tiếp đến là IIA và IIIA3, thấp nhất là trạng thái IIA $(12,04)$.

Tuy nhiên, các chỉ số Shannon và Wiener cho thấy rằng mức độ đa dạng loài ở trạng thái trạng thái IIIA3 là cao nhất $(\mathrm{H}=3,58)$ và có xu hướng giảm dần theo trạng thái thấp nhất là trạng thái IIA. Bên cạnh đó chỉ số $\mathrm{H}$ gần sát với $\mathrm{Hmax}$, điều này chứng tỏ mức độ da dạng loài ở các trạng thái rất đồng đều.

Chỉ số đồng đều $(\mathrm{J})$ dùng để đánh giá mức độ phong phú của loài xuất hiện trong quần xã, hay đánh giá mức độ đồng đều về số lượng cá thể của mỗi loài. Qua bảng kết quả cho thấy mức độ đồng đều cao nhất ở trạng thái IIIA3 $(0,91)$ và giảm dần theo trạng thái, thấp nhất ở trạng thái IIA $(0,81)$. Điều này cũng tương tự với chỉ số Sheldom: Cao nhất ở trạng thái IIIA3 $(0,59)$ và có xu hướng giảm dần theo trạng thái. Vì vậy, nhìn chung, trạng thái IIIA3 có mức độ phong phú, đa dạng về loài là cao nhất và số lượng cá thể giữa các loài được phân bố đồng đều hơn so với các trạng thái khác. Điều này thể hiện loại trạng thái này đã đi vào giai đoạn ổn định. Kết quả nghiên cứu này tương tự như một số nghiên cứu đã tiến hành ở Việt Nam (Bui, 2016).

\section{Kết Luận}

Nghiên cứu đã phân tích số liệu từ 20 OTC cho 4 trạng thái khác nhau là IIA, IIB, IIIA1 và IIIA3. Kết quả nghiên cứu cho thấy rằng số liệu tại các OTC là khá thuần nhất. Đường kính ngang ngực và chiều cao vút ngọn tăng dần theo trạng thái. Đường kính ở 4 trạng thái lần lượt là IIA: $11,25 \mathrm{~cm}$; IIB: $12,81 \mathrm{~cm}$; IIIA1: $15,94 \mathrm{~cm}$ và IIIA3: 20,30 cm. Kết quả mô hình tuyến tính hỗn hợp chứng minh rằng sinh trưởng cả về đường kính và chiều cao giữa các trạng thái rừng là thực sự khác biệt. Phân bố số cây theo đường kính thường có dạng giảm liên tục từ tổ đầu tiên. Còn phân bố số cây theo chiều cao thì đỉnh có dạng lệch trái. Kết quả mô hình hóa cho thấy rằng cả hai hàm Weibull và Khoảng cách có khả năng mô phỏng rất tốt cho phân bố thực nghiệm. Trong hai hàm thử nghiệm thì phân bố Weibull có khả 
Bảng 5. Thống kê số cây theo chất lượng cây rừng của 4 trạng thái

\begin{tabular}{ccccc}
\hline \multirow{2}{*}{ Trạng thái } & \multicolumn{3}{c}{ Chất Lượng } & \multirow{2}{*}{ Tổng } \\
\cline { 2 - 4 } & Tốt & Trung bình & Xấu & \\
\hline \multirow{2}{*}{ IIA } & 197 & 47 & 12 & 256 \\
& $76,95 \%$ & $18,36 \%$ & $4,69 \%$ & $100 \%$ \\
IIB & 238 & 32 & 16 & 286 \\
& $83,22 \%$ & $11,19 \%$ & $5,59 \%$ & $100 \%$ \\
IIIA1 & 101 & 46 & 39 & 186 \\
& $54,30 \%$ & $24,73 \%$ & $20,97 \%$ & $100 \%$ \\
IIIA3 & 171 & 53 & 18 & 242 \\
& $70,66 \%$ & $21,90 \%$ & $7,44 \%$ & $100 \%$ \\
\hline \multirow{2}{*}{ Tổng } & 707 & 178 & 85 & 970 \\
& $72,89 \%$ & $18,35 \%$ & $8,76 \%$ & $100,00 \%$ \\
\hline
\end{tabular}

Bảng 6. Tổ thành theo tỷ lệ số cây của mỗi loài trong lâm phần

\begin{tabular}{|c|c|}
\hline $\mathrm{TT}$ & Tố thành theo tỷ lệ số cây \\
\hline IIA & $\begin{array}{l}\text { 2,19 Núi Nái + 1,56 Ba Gạc + 1,13 Mò Roi + 0,55 Ba Soi + 0,55 Phân Mã } \\
\text { + 0,51 Lòng Trứng + 0,47 Đơn Nem + 0,39 Lá Nến + 2,66 LK (22 LK) }\end{array}$ \\
\hline IIB & $\begin{array}{l}\text { 1,64 Ba Gạc + 1,5 Phân Mã + 0,98 Mò Lá Nhỏ + 0,42 Màng Tang + 0,28 Ba Soi } \\
\text { + 0,28 Lộc Vừng + 0,24 Đơn Nem + 0,24 Mò Lá To + 0,21 Trẩu + 0,21 Lát Hoa } \\
\text { + 0,21 Đỏm Gai + 0,21 Sẻn Gai + 3,57 LK (44 LK) }\end{array}$ \\
\hline IIIA1 & $\begin{array}{l}\text { 1,4 Vàng Anh + 1,02 Chìa Vôi + 0,65 Lộc Vừng + 0,59 Nóng + 0,48 Nóng } \\
\text { + 0,43 Cà Lồ + 0,38 Kháo Vàng + 0,32 Trâm Trắng + 0,32 Trường Mật } \\
\text { + 0,27 Sảng Nhung + 0,27 Bã Đậu + 0,27 Thừng Mực Mỡ + 0,22 Thị Rừng } \\
\text { + 3,39 LK (39LK) }\end{array}$ \\
\hline IIIA3 & $\begin{array}{l}\text { 0,83 Gội Trắng + 0,7 Lộc Vừng + 0,62 Vàng Anh + 0,54 Chò Xanh + 0,5 Sồi } \\
+ \text { 0,45 Máu Chó Lá Nhỏ + 0,45 Trâm Trắng }+0,45 \text { Trường Mật }+ \text { 0,33 Mò Lá To } \\
\text { + 0,33 Chìa Vôi }+ \text { 0,33 Phân Mã + 0,29 Vỏ Sạn + 0,25 Táu Xanh + 0,21 Gội Nếp } \\
\text { + 0,21 Mò Lông }+0,21 \text { Nóng }+3,31 \text { LK }(36 \text { LK })\end{array}$ \\
\hline
\end{tabular}

Bảng 7. Kết quả tính toán chỉ số đa dạng của Lâm phần

\begin{tabular}{ccccc}
\hline Trạng thái & Margalef & Shannon - Wiener & $\mathrm{J}^{\prime}$ & Sheldom \\
\hline IIA & 12,04 & 2,75 & 0,81 & 0,52 \\
IIB & 22,39 & 3,31 & 0,82 & 0,49 \\
IIIA1 & 22,47 & 3,43 & 0,87 & 0,59 \\
IIIA3 & 21,39 & 3,58 & 0,91 & 0,69 \\
\hline
\end{tabular}

năng mô hình hóa tốt hơn.

Hệ số đường ảnh hưởng đã kiểm tra mức độ ảnh hưởng của các nhân tố đường kính ngang ngực, chiều cao vút ngọn và đường kính tán tới chất lượng cây rừng. Kết quả cho thấy rằng với cả bốn trạng thái thì hệ số ảnh hưởng trực tiếp (AHTT) đều có giá trị tuyệt đối lớn hơn hệ số ảnh hưởng gián tiếp (AHGT). Điều này chứng tỏ rằng chất lượng của các khu rừng ít bị ảnh hưởng của những nhân tố khác như khí hậu và các đại lượng điều tra khác. Biểu đồ của phân tích thành phần chính cho thấy rằng với cả bốn loại trạng thái rừng thì chất lượng cây rừng có mối quan hệ khá chặt với đường kính tán, chiều cao dưới cành và đường kính ngang ngực. Trong đó quan hệ chặt chẽ nhất với đường kính tán. Kết quả thống kê cho thấy rằng tỷ lệ cây chất lượng tốt cao nhất ở trạng thái IIB và thấp nhất ở trạng thái IIIA1. Sự khác biệt vệ chất lượng cây rừng giữa 4 trạng thái là thực sự rõ rệt.

Về tổ thành loài, ở trạng thái IIA và IIB là trạng thái phục hồi sau nương rẫy với tổ thành loài cây đa dạng và phong phú với chủ yếu các loài cây tiên phong ưu sáng mọc nhanh như: Núi 
Nái, Phân mã, Ba gạc, Mò lá nhỏ...; còn ở trạng thái IIIA1 và IIIA3 xuất hiện them nhiều loài cây chịu bóng, cấu trúc rừng ổn định đi vào khép tán với các loài cây gỗ như: Vàng anh, Chìa vôi, Cà Lồ, Lộc Vừng, Sồi... Chỉ số Shannon và Wiener và Simpson cho thấy rằng mức độ đa dạng loài ở trạng thái trạng thái IIIA3 là cao nhất $(\mathrm{H}=$ 3,58 ) và có $x u$ hướng giảm dần theo trạng thái thấp nhất là trạng thái IIA. Bên cạnh đó chỉ số $\mathrm{H}$ gần sát với $\mathrm{Hmax}$, điều này chứng tỏ mức độ da dạng loài ở các trạng thái rất đồng đều.

\section{Tài Liệu Tham Khảo (References)}

Bui, H. M. (2016). Structure and restoration of natural secondary forests in the Central Highlands, Vietnam. Dresden University of Technology, Dresden, Germany.

Bui, H. M., \& Bui, D. T. (2017). Applying linear mixed model (LMM) to analyze forestry data, checking autocorrelation and random effects, using R. Journal of Forestry Science and Technology 2, 17-26.

Bui, H. M., \& Le, T. X. (2017). Changes in structure and quality of natural forest overstorey in Kon Ka Kinh National Park, Gia Lai. Journal of Forestry Science 3, 85-95.

Gao, T., Hedblom, M., Emilson, T., \& Nielsen, B. A. (2014). The role of forest stand structure as biodiversity indicator. Forest Ecology and Management 330, 82-93.

Ho, R. (2013). Handbook of Univariate and Multivariate Data Analysis with IBM SPSS. Florida, USA: CRC Press.

Kint, R., \& Coe, R. (2005). Tree diversity analysis: A manual and software for common statistical methods for ecological and biodiversity studies. Nairobi, Kenya: World Agroforestry Centre.
Nguyen, T. H., Vu, H. T., \& Ngo, K. K. (2006). Statistics in forestry. Ha Noi, Vietnam: Agricultural Publishing House.

Richards, P. W. (1996). The tropical rain forest: An ecological study. Cambridge, United Kingdom: Cambridge University Press.

Rubén, V. (2015). Forest structure indicators based on tree size inequality and their relationships to airborne laser scanning. University of Eastern Finland, Kuopio, Finland.

Shiver, B. D., \& Borders, B. E. (1996). Sampling techniques for forest resources inventory. New York, USA: John Wiley \& Sons.

Spies, T. A. (1998). Forest Structure. In Trofymow, J. A., \& MacKinno, A. (Eds.). Proceedings of a workshop on Structure, Process, and Diversity in Successional Forests of Coastal British Columbia. Washington, USA: Washington State University Press.

Spies, T. A., \& Franklin, J. F. (1996). The diversity and maintenance of old-growth forests. In Szaro, R. C., \& Johnston, D. W. (Eds.). Biodiversity in managed Landscapes: Theory and Practice. New York, USA: Oxford University Press.

Tran, Q. H. (2010). Participation of community management in the buffer zone of Xuan Son National Park in Phu Tho province. (Unpublished bachelor's thesis). Thai Nguyen University, Thai Nguyen, Vietnam.

Vu, H. T., \& Pham, G. B. (1996). Forest investigation. Ha Noi, Vietnam: Agricultural Publishing House.

Zar, J. H. (2010). Biostatistical Analysis (5 $5^{\text {th }}$ ed.). New Jersey, USA: Prentice Hall, Upper Saddle River 